\title{
Cannabinoids, anxiety, and the periaqueductal gray
}

\author{
Viviane M. Saito and Fabrício A. Moreira \\ Universidade Federal de Minas Gerais, Brazil
}

\begin{abstract}
The use of Cannabis sativa by humans dates back several thousand years, for both its psychotomimetic and potential medicinal properties. As scientific research methods developed, the cannabinoids present in this herb were characterized, as well as their complex interface with the human central nervous system, provided by the activation of specific receptors. The subsequent description of an endogenous cannabinoid system in the mammalian brain shifted the notion of cannabis as a recreational drug to a therapeutic alternative for psychiatric disorders. However, the neuroanatomical sites mediating its effects have remained uncertain. In the present paper, we review recent data suggesting that the midbrain periaqueductal gray may be a structure involved in the anxiolytic-like effects of cannabinoids. Keywords: cannabis, endocannabinoids, anxiety, periaqueductal gray.
\end{abstract}

Received 16 February 2010; received in revised form 28 April 2010; accepted 28 April 2010. Available on line 26 June 2010

\section{Introduction}

The earliest record of Cannabis sativa use by humans was found approximately 12000 years ago (Beaulieu \& Rice, 2002). Cannabis is known to produce euphoria, sensory perception imbalance, tachycardia, antinociception, concentration difficulties, memory impairment, antiemesis, and increased appetite (Ameri, 1999; Di Marzo \& Matias, 2005). However, only in the last half-century have these effects of cannabis become better understood, attributable to the discovery and synthesis of its main psychoactive component, $\Delta^{9}$ tetrahydrocannabinol (THC). The psychotropic effects of marijuana are attributed to this compound. The plant has dozens of substances known as phytocannabinoids, which all share lipophilic properties and are still being studied for their possible beneficial effects in humans.

\section{Characterization of the endocannabinoid system}

Cannabinoids are natural or synthetic substances that resemble or derive from the phytocannabinoids described above. They induce their pharmacological effects in vivo by activating two receptor subtypes that

Viviane M. Saito, Programa de Pós-Graduação em Neurociências, Universidade Federal de Minas Gerais, Brazil. Fabrício A. Moreira, Departamento de Farmacologia, Instituto de Ciências Biológicas, Universidade Federal de Minas Gerais, Brazil. Correspondence regarding this article should be directed to: FabrícioA. Moreira, Departamento de Farmacologia, Instituto de Ciências Biológicas, Universidade Federal de Minas Gerais, Campus Pampulha, Av. Antônio Carlos, 6627, Belo Horizonte, MG, CEP 31270-901, Brazil. Tel.: +55-31-3409-2720. E-mail: fabriciomoreira@icb.ufmg.br have been identified and cloned: the $\mathrm{CB}_{1}$ receptor, which is highly expressed in the central nervous system (CNS) at presynaptic axon terminals (Devane, Dysarz, Johnson, Melvin, \& Howlett, 1988; Matsuda, Lolait, Brownstein, Young, \& Bonner, 1990), and the $\mathrm{CB}_{2}$ receptor, which is located mainly in peripheral tissues at the level of the immune system (Munro, Thomas, \& Abu-Shaar, 1993). The brain distribution of $\mathrm{CB}_{1}$ binding sites correlates with the effects of cannabinoids on emotional states. $\mathrm{CB}_{1}$ receptors are densely expressed in a group of structures hypothesized to be the neuroanatomical substrate for stress, aversion, fear, and anxiety, including the prefrontal cortex, amygdala, hippocampus, periaqueductal gray (PAG), and hypothalamus (Herkenham et al., 1990).

After the identification of the first cannabinoid receptor, the search for an endogenous ligand for this receptor began. The first endogenous cannabinoid ligand, or endocannabinoid, was discovered in 1992 when the arachidonic acid (AA) derivative arachidonoylethanolamide (AEA; also named "anandamide" from the Sanskrit "ananda," meaning "bliss") was isolated from porcine brain (Devane et al., 1992). Anandamide was found to induce pharmacological actions similar to those of cannabinoids, such as THC, and to be the principal endogenous ligand for $\mathrm{CB}_{1}$ receptors. 2-Arachidonoylglycerol (2-AG), another endocannabinoid and an arachidonic acid derivative, was then soon discovered by Mechoulam et al. (1995). These two ligands are considered the most biologically important endocannabinoids, though other endocannabinoids have also been described, including 2-arachidonylglyceryl ether (noladin), $O$-arachidonoylethanolamine (virodhamine), and $N$-arachidonoyldopamine (De Petrocellis \& Di Marzo, 


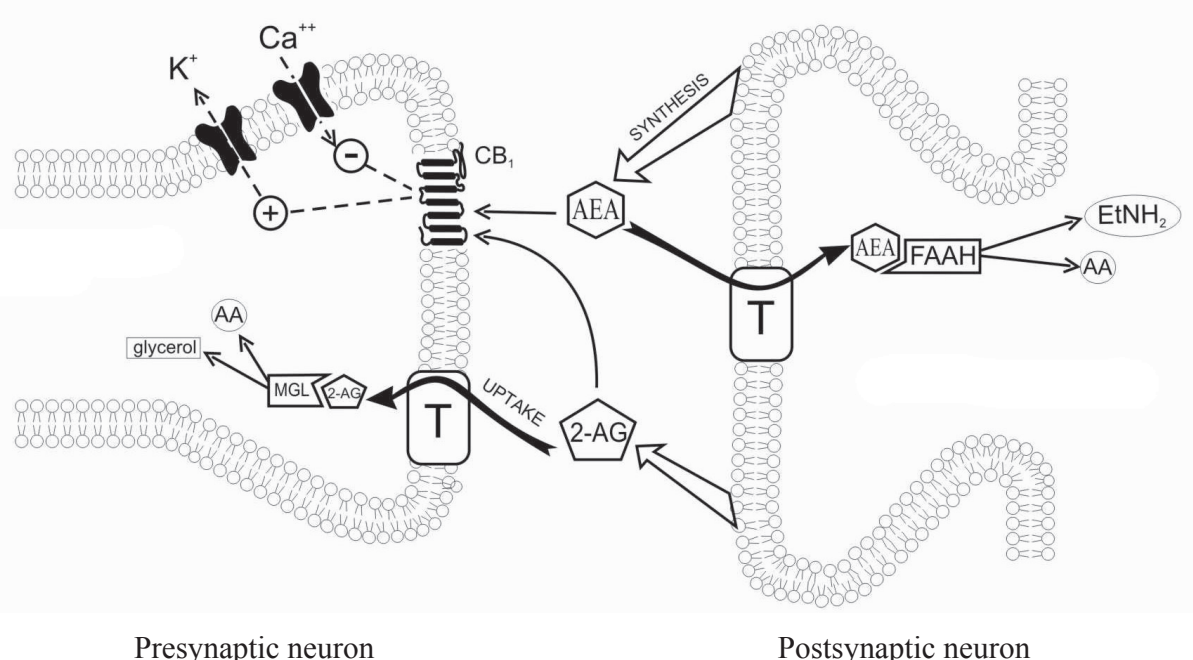

Figure 1. Illustration of endocannabinoid synthesis, retrograde signaling, and uptake.

2009). Endocannabinoids are believed to be produced from phospholipid precursors and are released upon demand after cellular depolarization or receptor stimulation in a calcium-dependent manner. Endocannabinoids are not stored in vesicles as classical neurotransmitters - they are promptly diffused from the postsynaptic neuron to the synaptic cleft. They then bind to presynaptic $\mathrm{CB}_{1}$ receptors to exert their effects. By activating $\mathrm{CB}_{1}$ receptors, endocannabinoids can inhibit both excitatory and inhibitory neurotransmission from presynaptic terminals (Wilson \& Nicoll, 2002). Termination of endocannabinoid signaling occurs through a reuptake mechanism (possibly mediated by a selective transporter) and subsequent enzymatic metabolism. AEA is hydrolyzed by the enzyme fatty acid amide hydrolase (FAAH), whereas 2-AG undergoes catabolism by a different enzyme, monoacylglyceride lipase (De Petrocellis \& Di Marzo, 2009). Altogether, the cannabinoid receptors, their endogenous ligands, and their respective catabolic enzymes constitute the endocannabinoid system. Despite

Table 1. Timeline of cannabis pharmacology.

\begin{tabular}{|c|c|}
\hline 1964 & Identification of $\Delta^{9}-\mathrm{THC}$ as the main psychoactive compound of cannabis \\
\hline 1980 & Development of synthetic cannabinoids \\
\hline 1988 & Identification of the $\mathrm{CB}_{1}$ receptor \\
\hline 1990 & Cloning of the $\mathrm{CB}_{1}$ receptor \\
\hline 1992 & $\begin{array}{l}\text { Identification of the } \mathrm{CB}_{2} \text { receptor } \\
\text { Discovery of the endogenous ligand anandamide }\end{array}$ \\
\hline 1993 & Cloning of the $\mathrm{CB}_{2}$ receptor \\
\hline 1994 & Development of a $\mathrm{CB}_{1}$ antagonist \\
\hline 1995 & Discovery of endocannabinoids 2-AG and palmitoylethanolamide \\
\hline 1997 & Development of $\mathrm{a} \mathrm{CB}_{2}$ antagonist \\
\hline 1998 & $\begin{array}{l}\text { Evidence of the analgesic properties of endocannabinoids } \\
\text { Development of knockout mice lacking the gene expressing } \mathrm{CB}_{1} \text { receptor }\end{array}$ \\
\hline 2000 & Development of knockout mice lacking the gene expressing $\mathrm{CB}_{2}$ receptor \\
\hline
\end{tabular}


enormous advances in this field, the endocannabinoid system has not been fully characterized, and many of its mechanisms remain unknown.

Remarkable advances in cannabinoid pharmacology have occurred based on the identification of endocannabinoid compounds and the development of potent and selective synthetic cannabinoid agonists, antagonists, and enzymatic blockers.

\section{Cannabinoids and anxiety}

The anxiolytic-like effects of cannabinoids have been investigated in several studies in humans and animals. Anatomical, biochemical, and pharmacological evidence indicates that endocannabinoid signaling is important in the control of emotional behavior, although its effects may be contradictory in humans and animals, depending on such variables as drug dose, genetic background, and environmental context (Moreira, Aguiar, \& Guimarães, 2009; Viveros, Marco, \& File, 2005). Even under recreational conditions, marijuana users describe paradoxical effects on anxiety (Zuardi, Crippa, \& Guimarães, 2008). In animal studies, systemic injections of $\Delta^{9}$-THC or its synthetic analogs have exerted bidirectional effects on anxiety-related behaviors, eliciting either anxiogenic- or anxiolytic-like responses. Lower doses of cannabinoids are apparently anxiolytic, whereas higher doses may exacerbate anxious behavior (Viveros et al., 2005; Zuardi et al., 2008). Some of the possible reasons for these controversial effects include the recruitment of other neurocircuits, the specific pharmacological pathway investigated, and the sensitivity of the model employed.

An integrative hypothesis for the biphasic effects of cannabinoids on anxiety proposes that they may occur as a result of the distinct roles of $\mathrm{CB}_{1}$ receptors in different brain regions, in addition to the drug and dose range used and the differential sensitivity of the receptors to these compounds (Viveros et al., 2005). The biphasic effects may also be related to the close cooperation between the endocannabinoid system and other neurotransmitter circuits, including $\gamma$-aminobutyric acid and glutamate systems (Moreira et al., 2009). In addition to direct agonism of cannabinoid receptors, pharmacological studies may employ other strategies such as inhibition of endocannabinoid uptake or metabolism. Pharmacological blockade of FAAH by URB597 and URB532 produces anxiolytic-like effects in the elevated zero-maze in adult rats, suggesting that increased AEA levels may interfere with the modulation of emotional states. Therefore, FAAH inhibition may be a valuable approach for anti-anxiety therapy because it is not accompanied by any signs of cannabinoid intoxication (Kathuria et al., 2003). Thus, augmentation of endocannabinoid signaling has anxiolytic effects, whereas blockade or genetic deletion of $\mathrm{CB}_{1}$ receptors has anxiogenic properties (for review, see Patel \& Hillard, 2009).

A functional approach for investigating the role of the endocannabinoid system as part of the complex circuitry that regulates anxiety arises from the high density of $\mathrm{CB}_{1}$ receptors in brain structures presumably involved in anxiety-related responses, such as the PAG. This midbrain structure has been proposed to be involved in the perception of pain, "fight-or-flight" responses, and behaviors related to fear, anxiety, and panic (Del-Ben \& Graeff, 2009). To thoroughly investigate the overall interaction between the endocannabinoid system and the PAG on anxiety-like behaviors, experiments with intracerebral drug injections have been performed in rats. The effects of intra-PAG injections of cannabinoids have been evaluated in diverse animal models.

Moreira et al. (2007) showed that direct AEA injection into the PAG increased exploration of the open arms of the elevated plus maze, an animal model predictive of anxiety-like behavior. This anxiolyticlike effect was prevented by pretreatment with the $\mathrm{CB}_{1}$ receptor antagonist AM251, whereas the AEA uptake/ metabolism inhibitor AM404 potentiated this effect. Subsequent studies extended these data to other models. Local injection of cannabinoids into the PAG also induced anxiolytic-like effects in the Vogel conflict test, an animal model based on the suppression of punished responses (Lisboa, Resstel, Aguiar, \& Guimarães, 2008). Direct activation of $\mathrm{CB}_{1}$ receptors by intra-PAG injection of AEA or AM404 also blocked the expression of conditioned responses; this effect was blocked by a $\mathrm{CB}_{1}$ antagonist, implicating $\mathrm{CB}_{1}$ receptors in the modulation of conditioned responses (Resstel, Lisboa, Aguiar, Corrêa, \& Guimarães, 2008).

The bimodal effects on anxiety produced by pharmacological tools that enhance endocannabinoid signaling appear to rely also on fine differences between the animal models employed to investigate its influence on behavior (Moreira et al., 2009). Nevertheless, because of its reliable, stable effects on anxiety, blockade of endocannabinoid hydrolysis via inactivation of FAAH appears to be a promising alternative for the development of anti-anxiety drugs, although many aspects of the endocannabinoid system and the utility of other cannabinoids remain uncertain.

\section{Conclusion}

The endocannabinoid system is a ubiquitous signaling system that has important regulatory functions in the CNS. Extensive biochemical and neurobiological research has attempted to elucidate how the brain interacts with the major components of Cannabis sativa and their endogenous analogs, the endocannabinoids. The distribution of cannabinoid receptors in specific structures in the mammalian brain 
indicates that the endocannabinoid system participates in the regulation of mood and emotional behaviors. $\mathrm{CB}_{1}$ receptors are broadly distributed throughout the PAG, which has been considered an important component of a network of brain structures that process anxiety-like behavior (Graeff \& Del-Ben, 2008). Animal models and pharmacological manipulation of the endocannabinoid system, either by stimulating the production and release of endocannabinoids or by blocking their catabolism, have suggested the importance of this system in emotional behavior. Scientific research has explored the controversial, bimodal effects of cannabinoids on human anxiety, revealing the delicate balance between the potential therapeutic use and unique side-effect profile of cannabis and cannabinoids. Any attempt to develop endocannabinoid-based therapeutics for anxiety disorders must weigh the benefits against any undesirable or unpredictable effects.

\section{References}

Ameri, A. (1999). The effects of cannabinoids on the brain. Progress in Neurobiology, 58, 315-348.

Beaulieu, P., \& Rice, A.S.C. (2002). Pharmacologie des dérivés cannabinoïdes: applications au traitement de la douleur? Annales Françaises d'Anesthésie et de Réanimation, 21, 493-508.

De Petrocellis, L., \& Di Marzo, V. (2009). An introduction to the endocannabinoid system: from the early to the latest concepts. Best Practice and Research in Clinical Endocrinology and Metabolism, 23, 1-15.

Del-Ben, C.M., \& Graeff, F.G. (2009). Panic disorder: is the PAG involved? Neural Plasticity, 2009, Article ID 108135.

Devane, W.A., Dysarz 3rd, F.A., Johnson, M.R., Melvin, L.S., \& Howlett, A.C. (1988). Determination and characterization of a cannabinoid receptor in rat brain. Molecular Pharmacology, 34, 605-613.

Devane, W.A., Hanus, L., Breuer, A., Pertwee, R.G., Stevenson, L.A., Griffin, G., Gibson, D., Mandelbaum, A., Etinger, A., \& Mechoulam, R. (1992). Isolation and structure of a brain constituent that binds to the cannabinoid receptor. Science, 258, 1946-1949.

Di Marzo, V., \& Matias, I. (2005). Endocannabinoid control of food intake and energy balance. Nature Neuroscience, 8, 585-589.

Graeff, F.G., \& Del-Ben, C.M. (2008). Neurobiology of panic disorder: from animal models to brain neuroimaging. Neuroscience and Biobehavioral Reviews, 32, 1326-1335.

Herkenham, M., Lynn, A.B., Little, M.D., Johnson, M.R., Melvin, L.S., de Costa, B.R., \& Rice, K.C. (1990). Cannabinoid receptor localization in brain. Proceedings of the National Academy of Sciences of the United States of America, 87, 1932-1936.

Kathuria, S., Gaetani, S., Fegley, D., Valiño, F., Duranti, A., Tontini, A., Mor, M., Tarzia, G., La Rana, G., Calignano, A., Giustino, A., Tattoli, M., Palmery, M., Cuomo, V., \& Piomelli, D. (2003). Modulation of anxiety through blockade of anandamide hydrolysis. Nature Medicine, 9, 76-81.

Lisboa, S.F., Resstel, L.B., Aguiar, D.C., \& Guimarães, F.S. (2008). Activation of cannabinoid $\mathrm{CB} 1$ receptors in the dorsolateral periaqueductal gray induces anxiolytic effects in rats submitted to the Vogel conflict test. European Journal of Pharmacology, 593, 73-78.

Matsuda, L.A., Lolait, S.J., Brownstein, M.J., Young, A.C., \& Bonner, T.I. (1990). Structure of a cannabinoid receptor and functional expression of the cloned cDNA. Nature, 346, 561-564.

Mechoulam, R., Ben-Shabat, S., Hanus, L., Ligumsky, M., Kaminski, N.E., Schatz, A.R., Gopher, A., Almog, S., Martin, B.R., Compton, D.R., Pertwee, R.G., Griffin, G., Bayewitch, M., Barg, J., \& Vogel, Z. (1995). Identification of an endogenous 2-monoglyceride, present in canine gut, that binds to cannabinoid receptors. Biochemical Pharmacology, 50, 83-90.

Moreira, F.A., Aguiar, D.C., \& Guimarães, F.S. (2007). Anxiolyticlike effect of cannabinoids injected into the rat dorsolateral periaqueductal gray. Neuropharmacology, 52, 958-965.

Moreira, F.A., Aguiar, D.C., Campos, A.C., Lisboa, S.F., Terzian, A.L., Resstel, L.B., \& Guimarães, F.S. (2009). Antiaversive effects of cannabinoids: is the periaqueductal gray involved? Neural Plasticity, 2009, Article ID 625469.

Munro, S., Thomas, K.L., \& Abu-Shaar, M. (1993). Molecular characterization of a peripheral receptor for cannabinoids. Nature, $365,61-65$.

Patel, S., \& Hillard, C.J. (2009) Role of endocannabinoid signaling in anxiety and depression. In D.A. Kendall \& S. Alexander (Eds.), Behavioral neurobiology of the endocannabinoid system (pp. 347371). Dordrecht: Springer-Verlag.

Resstel, L.B., Lisboa, S.F., Aguiar, D.C., Corrêa, F.M.A., \& Guimarães, F.S. (2008). Activation of CB1 cannabinoid receptors in the dorsolateral periaqueductal gray reduces the expression of contextual fear conditioning in rats. Psychopharmacology, 198, 405-411.

Viveros, M.P., Marco, E.M., \& File, S.E. (2005). Endocannabinoid system and stress and anxiety responses. Pharmacology Biochemistry and Behavior, 81, 331-342.

Wilson, R.I., \& Nicoll, R.A. (2002). Endocannabinoid signaling in the brain. Science, 296, 678-682.

Zuardi, A.W., Crippa, J.A.S., \& Guimarães, F.S. (2008). Cannabis e saúde mental. São Paulo: FUNPEC-Editora. 